\title{
Tunicamycin Anticancer Drug May Reliable to Treat Coronavirus Disease-19
}

\author{
Ali Adel Dawood ${ }^{1 *}$, Haitham Abdul-Malik Alnori² \\ ${ }^{1}$ Department of Anatomy, Medical Biology, College of Medicine, University of Mosul, Mosul, Iraq; ${ }^{2}$ Department of Surgery, \\ College of Medicine, University of Mosul, Mosul, Iraq
}

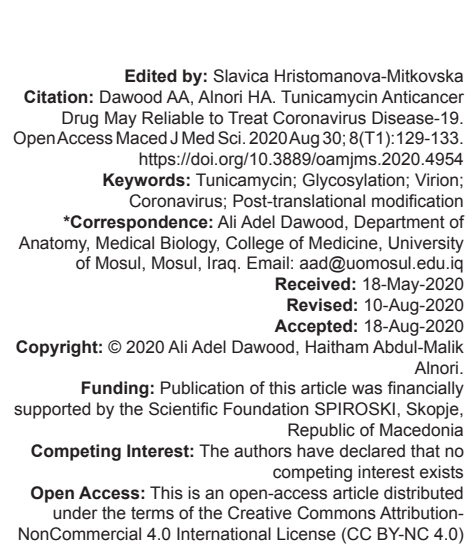

\section{Abstract}

BACKGROUND: SARS-CoV-2 outbreaks remains a medical and economic challenge, due to the lack of a suitable drug or vaccine. The glycan in some proteins plays an important role in protein folding, sorting, transport, and oligomerization, so the hindering of $\mathrm{N}$-linked glycosylation of glycoproteins will prevent assembly of the virion. Tunicamycin anticancer drug inhibits the $\mathrm{N}$ - linked glycan.

AIM: This study aimed to find out the mechanism action of tunicamycin on the viral glycoproteins.

RESULTS: The growth of the virus in the presence of tunicamycin conducted in the production of non-infectious and absence of spike protein (spikeless virions). Tunicamycin inhibits E2, S, and M glycoproteins of coronaviruses. Tunicamycin has also diminished glycosylation of PTMs such as HE, and 8ab of SARS-CoV. Finally,

CONCLUSION: This study recommends using this drug to treat the SARS-CoV-2.

\section{Introduction}

Since the last December, a new coronavirus has been a challenge for all of the world. The reason of elevation number of infections and fatality that the researchers failed to find suitable drug or vaccine to stem the outbreaks [1]. A few studies focused on the effect of $\mathrm{N}$ - and O-glycosylation through the process of virion assembly. N-linked glycosylation is the attachment of an oligosaccharide (glycan), to a nitrogen atom an asparagine (Asn) residue of a protein. This linkage is important for the structure and function of some eukaryotic proteins. Severe acute respiratory syndrome coronavirus (SARS-CoV) is one of viruses that contain $\mathrm{N}$-linked glycoproteins which are glycosylated by the transfer of core oligosaccharides from a dolichol pyrophosphate carrier to asparagine residues on the polypeptide [2]. O-linked glycosylation is the attachment of a sugar molecule to the oxygen atom on serine (Ser) or threonine (Thr) residues in a protein. O-glycosylation is a post-translational modification (PTM) that occurs after the protein has been synthesized. It occurs either in the endoplasmic reticulum or Golgi apparatus and it influences on the stability and regulation of protein [3]. The main function of O-glycan is allowing recognition of foreign material and controlling cell metabolism. The changes in O-glycosylation are important in many diseases including cancer, diabetes Alzheimer's, as well as some viral infections [4]. Because glycosylation and transport of viral proteins depend on cellular processes, prevention this process depends on the type of the viral protein and the activity of the substrate to diminish it. Coronavirus glycoproteins may be glycosylated by a different mechanism. This glycoproteins serve as a useful model for the study of $\mathrm{N}$ - and O-linked glycoproteins [5].

\section{The Role of Tunicamycin (TM)}

TM, an antibiotic, was produced by Streptomyces clavuligerus and Streptomyces lysosuperficus bacteria along with several other species and a proposed biosynthetic pathway was characterized. TM is a white crystalline powder which is soluble in alkaline water, pyridine, and hot methanol, slightly soluble in ethanol and $n$-butanol and insoluble in acetone, ethyl acetate, chloroform, benzene, and acidic water [6]. 


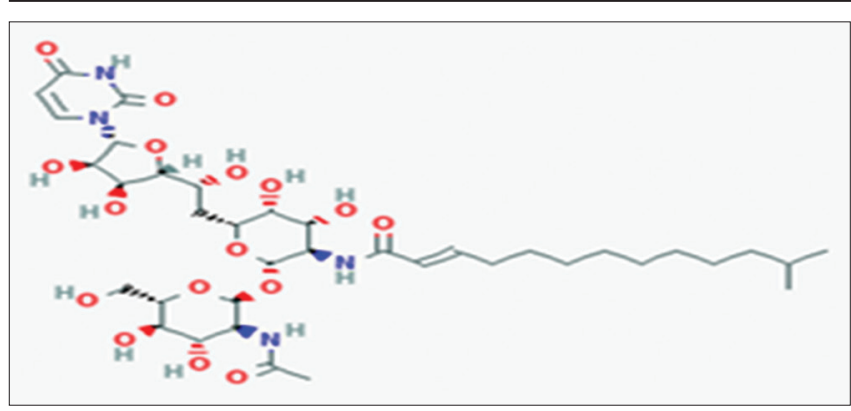

Figure 1: The structure of tunicamycin drugbank

TM, Figure 1, is an analog of UDP-Nacetylglucosamine, interfered with the formation of dolichol pyrophosphate-acetylglucosamine which acts as a carrier for $\mathrm{N}$-glycosidic linkage of core oligosaccharides to asparagine (Asn) residues on glycoproteins. The bacteria utilize the enzymes in the tun gene cluster (TunA-N) to make TMs. Several of cellular glycoproteins contain glycosylation linkage such as immunoglobulins, fetuin, thyroglobulin, and proteoglycan. Tunicamycin inhibits the first step in the biosynthesis of $\mathrm{N}$-glycosylation linked in the ER resulting produced many misfolded proteins [7]. When the antibiotic blocks glycosylation of N-glycans, the cell cycle arrests at the G1 phase in human cells. The previous studies suggested that TM may work as a therapeutic drug against cancer cells as it has been shown to sensitize human colon and prostate cancer cells to TRAIL-induced apoptosis. The inhibited glycosylation of the structural glycoproteins was showed in alphaviruses, bunyaviruses, herpesviruses, and myxoviruses and all other viruses possess glycoprotein envelopes. Han et al. proposed that inhibition of the $\mathrm{N}$-linked glycan biosynthesis by TM may be a promising therapeutic strategy for enhancing the sensitivity of cancer cells to trastuzumab [8].

\section{Mechanism of Action of TM}

TM inhibits the reverse reactions in the first step of the biosynthesis of $\mathrm{N}$-linked oligosaccharides in cells. It prevents the formation of UDP-N-acetylglucosamine from $\mathrm{N}$-acetylglucosaminylpyrophosphoryl dolichol. The inhibition is increased by pre-incubating the enzyme with antibiotic for up to $5 \mathrm{~min}$ before addition the substrate. The addition of phosphatidylcholine at the concentration up to $20 \mathrm{mM}$ does not affect the inhibition regardless of whether it was added during the pre-incubation or at the same time at the substrate. TM binds to the heat denatured microsomal particles of aorta as shown by the fact that pre-incubation of the antibiotic with these particles prevented the inhibition of the $N$-acetylglucosamin-1-phosphate transferase [9].

\section{The Glycosylation of E1 and E2 Glycoproteins of Coronavirus}

The transmembrane glycoprotein El composed of three domains: A glycosylated domain projects from the envelope. The second domain lies within the membrane, and the third domain interacts with the nucleocapsid inside the viral envelope. El may be an O-linked glycoprotein [10]. Glycosylation of El appears post-translational event. The glycoprotein E2 forms the large petal-shaped peplomers characteristic of the coronavirus envelope. E2 is a $180 \mathrm{kDa}$ which can be cleaved by trypsin to yield two $90 \mathrm{kDa}$ components. It has been recorded that TM inhibits formation of the E2 glycoprotein but does not prevent synthesis or glycosylation of the glycoprotein El through the formation or releasing of virion from the infected cell. Moreover, the shift from the non-glycosylated $20 \mathrm{kDa}$ form to the glycosylated $23 \mathrm{kDa}$ form does not inhibit by TM [11], [12]. This provides indirect evidence that $\mathrm{E} 1$ is not an N-linked glycoprotein but may be an O-linked glycoprotein. Although El glycoproteins are more negatively charged than those of $\mathrm{E} 2$, these glycoproteins differ in carbohydrate composition, electrophoretic patterns of glycopeptides, and response to the antibiotic [13]. These data suggested that E1 is an O-linked glycoprotein while E2 is an $\mathrm{N}$-linked glycosylation. In contrast, the effects of TM on the synthesis and glycosylation of the two SARS-CoV-E glycoproteins have permitted tentative assignment of functions to these proteins [14].

\section{Protein \\ The Glycosylation of Coronavirus S}

Since the 1980s, the N-linked glycosylation S protein of coronavirus was defined for hepatitis virus MHV. S protein in the rough ER was found to acquire high mannose oligosaccharides. It has been found that the Golgi transport blocker (monensin) inhibited the transport of S protein from trans-Golgi network to the cell surface [15]. Other studies revealed that MHV $\mathrm{S}$ protein also modified the $\mathrm{N}$-linked glycosylation of bovine coronavirus BCoV, alpha-coronavirus transmissible gastroenteritis virus (TGEV), and gamma-coronavirus infectious bronchitis virus (IBV). The high mannose oligosaccharides of SARS-CoV S protein were trimerized as early as $30 \mathrm{~min}$ post-entry into ER, before the acquisition of complex glycans in the Golgi apparatus using pulse-chase experiments coupled with fractionation. Then, the maturation status of $S$ protein can be monitored by its sensitivity to endoglycosidase $\mathrm{H}$. This enzyme hydrolyzes the high mannose glycans [16]. After that, the structure of $\mathrm{N}$-linked glycosylation of $\mathrm{S}$ protein was determined using mass spectrometry. This linked was enriched with high mannose, hybrid and complex glycans with 
or without bisecting $N$-acetyl-galactosamine (GalNAc), and core fucose. A 12 out of 23 putative glycosylation sites detected of SARS-CoV S protein were actually glycosylated [17].

The SARS-CoV $S$ protein has two domains $\mathrm{S} 1$ and S2. When the S1 domain of bovine-CoV S protein was cloned and expressed in insect cells, the mature $S$ protein was glycosylated and bound by neutralizing monoclonal antibodies. On the other hand, the infected cells with TGEV in the presence of TM, the antigenicity of both $S$ and $M$ protein, were significantly reduced [18]. This may confirm that TM is an inhibitor factor of the glycosylation proteins. It has been demonstrated that the inhibition of $\mathrm{N}$-linked glycosylation by TM or removal of $\mathrm{N}$-linked glycans by PNGase $F$ reduced TGEV-induced IFN- $\alpha$ production. Therefore, the N-linked glycans on SARS-CoV S protein may be a pathogen associated molecular pattern recognized by host pattern recognition receptors. These receptors are activated downstream antiviral innate immune response. The growth of coronavirus in the presence inhibitor TM resulted in the production of spikeless, non-infectious virions which were devoid of S protein [19], [20].

\section{Protein}

\section{The Glycosylation of Coronavirus M}

$M$ protein of coronaviruses is the most abundant protein comprising of 220-260 amino acids. It plays a central role of the viral assembly. $M$ protein is a multipass transmembrane protein with a short N-terminal ectodomain, three hydrophobic TM domains, and a large C-terminal endodomain. O-linked glycosylation of the mouse hepatitis virus $M$ protein was first revealed in 1981. It was noted that in the presence of TM, M protein was still normally produced and glycosylated, resulting in the formation of none infectious virions containing normal amounts of $\mathrm{N}$ and M protein, but lacking S completely [21], [22].

Distinct from the O-linked glycosylation perceived in the $\mathrm{M}$ protein of bovine-coronavirus $\mathrm{BCoV}$, human-coronavirus $\mathrm{HCoV}-\mathrm{OC} 43$, alpha-coronavirus TGEV, gamma-coronavirus IBV, and turkey enteric coronavirus is all modified by N-linked glycosylation. This linked of $M$ protein is sensitive to endoglycosidase $\mathrm{H}$ and can be inhibited by TM. The $\mathrm{N}$-linked glycosylation sites were mapped to N3 and N6 of IBV. M protein of betacoronaviruses in other lineages is also $\mathrm{N}$-linked glycosylated [23]. For example, SARS-CoV M protein contains a single $\mathrm{N}$-glycosylation site at $\mathrm{N} 4$. When transiently transfected as a C-terminally FLAG-tagged protein, SARS-CoV M protein was found to obtain high mannose $\mathrm{N}$-glycans and was modified into complex $\mathrm{N}$-glycans in the Golgi. Although the glycosylation of the coronavirus $\mathrm{M}$ protein is a strongly conserved feature, this glycosylation is not important for virus assembly or replication [24], [25].
The Glycosylation of Coronavirus Nonstructural Proteins nsp3 and nsp4

Some of the luminal domains of nsps coronaviruses proteins undergo $\mathrm{N}$-linked glycosylation in the ER. For instance, MHV nsp3 is inserted into ER cotranslationally and glycosylated at N1525. Glycosylation of nsp4 was detected in IBV at N48 residue while for the nsp4 of MHV, two glycosylation sites were predicted at N176 and N237 residues. Till now, no study supports that TM inhibits $\mathrm{N}$-linked glycans either in nsp3 or nsp4 [26], [27], [28].

\section{Proteins}

\section{The Glycosylation of Coronavirus PTMs}

Coronavirus genome encodes various accessory proteins called apart from the structural and non-structural proteins (PTMs), most of which share no homology to any known proteins. However, some of the PTMs accessory proteins are incorporated in mature virions, others have been concerned in the modulation of host immune response and in vivo pathogenesis. One of the PTM proteins is HE protein which is a part of beta-coronaviruses $S$ protein. The $\mathrm{HE}$ protein of bovine $\mathrm{CoV}$ was also shown to be glycosylated when expressed using human adenovirus vector. Furthermore, HE protein of MHV was found to be modified by $\mathrm{N}$-linked glycosylation and was inhibited by TM but not monensin. The importance of $\mathrm{N}$-linked glycosylation of coronavirus HE protein has not been fully characterized [14], [29].

The O-linked glycosylation of SARS-CoV 3a protein and $M$ shares the same $\mathrm{N}$-exo/C-endo membrane topology. The both proteins contain three TM domains. O-linked glycans of the SARS-CoV protein $3 a$ are resistant to the treatment of PNGase F, and pulse-chase analysis suggested that the oligosaccharides were acquired post-translationally. Protein $3 \mathrm{a}$ has been implicated in modulating host immune response [30], [31].

The sgRNA8 of SARS-CoV encodes a single protein 8ab. A 29-nt deletion in the center split open reading frame ORF8 into two smaller frames, encoding proteins $8 \mathrm{a}$ and $8 \mathrm{~b}$, respectively. The $8 \mathrm{ab}$ protein is cotranslationally smuggled into the ER and is $\mathrm{N}$-linked glycosylated at N81. The 8b protein is synthesized in the cytosol and not modified. Both proteins $8 \mathrm{~b}$ and $8 \mathrm{ab}$ were shown to interact and modified by ubiquitination. The glycosylation at N81 stabilized 8ab protein and protected it from proteasomal degradation. Protein $8 \mathrm{~b}$ is unstable and undergoes rapid proteasomal degradation. The ubiquitinated $8 \mathrm{~b}$ and $8 \mathrm{ab}$ may mediate rapid degradation of IRF3 and regulate host antiviral innate immunity. The inhibition $\mathrm{N}$-linked glycosylation of SARS-CoV 8ab protein by TM is not completely understood [32], [33]. 


\section{Conclusions}

The transmembrane structural proteins $S$, E, M, nsp3, nsp4, and accessory proteins (HE, 3a, and $8 \mathrm{ab}$ ) of the most coronavirus family are modified by glycosylation. Although the $\mathrm{M}$ proteins of betacoronavirus adopt the special O-linked glycosylation, the $\mathrm{M}$ proteins of the other coronaviruses are modified by $\mathrm{N}$-linked glycosylation. It has been registered that glycosylation of coronavirus $\mathrm{S}$ protein is essentially $\mathrm{N}$-linked. The folding and intracellular trafficking $\mathrm{N}$-linked glycans of the coronavirus S protein also constitute a significant part of conformation of mature protein. TM inhibits formation of the coronavirus E2 glycoprotein but does not prevent synthesis or glycosylation of the glycoprotein El. The antigenicity of TGEV $S$ and $M$ protein was significantly reduced in the presence of TM. M protein of the most Coronaviridae is sensitive to endoglycosidase $\mathrm{H}$ and can be inhibited by TM. Lack information about the effect TM on SARS-CoV N-linked glycans ns 3 and ns4. HE and 8 ab proteins of SARS-CoV glycosylation are inhibited by TM. Although TM inhibits $\mathrm{N}$-linked glycosylation of coronaviruses glycoproteins, no drug available to inhibit O-linked glycosylation has been identified yet.

We concluded that TM inhibits E2, S, and M glycoproteins of coronaviruses. TM is also diminished glycosylation of PTMs such as HE and 8ab of SARS-CoV. Since TM has long been used as an anticancer and has the ability to inhibit glycoproteins of coronaviruses, we recommend to use this drug to treat the SARS-CoV-2.

\section{Acknowledgement}

The authors send thank to the University of Mosul.

\section{References}

1. Dawood A. Mutated COVID-19, may foretells mankind in a great risk in the future. New Microbes New Infect. 2020;35:100673. https://doi.org/10.1016/j.nmni.2020.100673

PMid:32292587

2. Merlieg JP, Sebbane R. Inhibition of glycosylation with tunicamycin blocks assembly of newly synthesized acetylcholine receptor subunits in muscle C. J Biol Chem. 1982;257(5):2694-701.

3. Locker JK, Griffiths G, Horzinek MC, Rottier PJ. O-glycosylation of the coronavirus $M$ protein. Differential localization of sialyltransferases in $\mathrm{N}$-and O-linked glycosylation. J Biol Chem. 1992;267(20):14094-101.

PMid:1629209
4. Lapps W, Hogue BG, Brian DA. Deduced amino acid sequence and potential O-glycosylation sites for the bovine coronavirus matrix protein. Adv Exp Med Biol. 1987;218:123-9. https://doi. org/10.1007/978-1-4684-1280-2_14

PMid:3434434

5. Yamada YK, Yabe M, Ohtsuki T, Taguchi F. Unique N-linked glycosylation of murine coronavirus MHV-2 membrane protein at the conserved O-linked glycosylation site. Virus Res. 2000;66(2):149-54. https://doi.org/10.1016/ s0168-1702(99)00134-3

PMid:10725548

6. Shiraishi T, Yoshida T, Nakata S, Horinaka M, Wakada M, Mizutani $Y$, et al. Tunicamycin enhances tumor necrosis factorrelated apoptosis-inducing ligand-induced apoptosis in human prostate cancer cells. Cancer Res. 2005;65(14):6364-70. https://doi.org/10.1158/0008-5472.can-05-0312 PMid:16024639

7. Takatsuki A, Tamura G. Inhibition of glycoconjugate biosynthesis by tunicamycin. Tunicamycin. Jap Sci Soc Pre. 1982;(3):35-70.

8. Han X, Zhang X, Li H, Huang S, Zhang S, Wang F, et al. Tunicamycin enhances the antitumor activity of trastuzumab on breast cancer in vitro and in vivo. Oncotarget. 2015;6(36):38912-25. https://doi.org/10.18632/oncotarget.5334 PMid:26498681

9. Heifetz A, Keenan RW, Elbein D. Mechanism of action of tunicamycin on the UDP-GlcNAc:dolichyl-phosphate GIcNAc1-phosphate transferase. Biocem. 1979;18(11):2186-92. https:// doi.org/10.1021/bi00578a008

PMid:444447

10. Niemann H, Boschek B, Evans D, Rosing M, Tamura T, Klenk HD. Post-translational glycosylation of coronavirus glycoprotein E1: Inhibition by monensin. EMBO J. 1982;1(12):1499-504. https:// doi.org/10.1002/j.1460-2075.1982.tb01346.x PMid:6327272

11. Luytjes W, Sturman LS, Bredenbeek PJ. Primary structure of the glycoprotein E2 of coronavirus MHV-A59 and identification of the trypsin cleavage site. Virology. 1987;161(2):479-87. https://doi.org/10.1016/0042-6822(87)90142-5 PMid:2825419

12. Corse $E$, Machamer CE. Infectious bronchitis virus $E$ protein is targeted to the Golgi complex and directs release of virus-like particles. J Virol. 2000;74(9):4319-26. https://doi.org/10.1128/ jvi.74.9.4319-4326.2000

PMid:10756047

13. Tooze SA, Tooze J, Warren GG. Site of addition of $\mathrm{N}$-acetyl-galactosamine to the $\mathrm{E} 1$ glycoprotein of mouse hepatitis virus-A59. J Cell Biol. 1988;106(5):1475-87. https:// doi.org/10.1083/jcb.106.5.1475 PMid:2836431

14. Holmes KV, Doller EW, Sturman LS. Tunicamycin resistant glycosylation of coronavirus glycoprotein: Demonstration of a novel type of viral glycoprotein. Virology. 1981;115(2):334-4. https://doi.org/10.1016/0042-6822(81)90115-x PMid:7314449

15. Yamada Y, Liu DX. Proteolytic activation of the spike protein at a novel RRRR/S motif is implicated in furin-dependent entry, syncytium formation, and infectivity of coronavirus infectious bronchitis virus in cultured cells. J Virol. 2009;83(17):8744-58. https://doi.org/10.1128/jvi.00613-09 PMid:19553314

16. Lavillette D, Barbouche R, Yao Y, Boson B, Cosset FL, Jones IM et al. Significant redox insensitivity of the functions of the SARS-CoV spike glycoprotein: Comparison with HIV envelope. J Biol Chem. 2006;281(14):9200-4. https://doi.org/10.1074/jbc. m512529200 
PMid:16418166

17. Shen S, Tan T, Tan YJ. Expression, glycosylation, and modification of the spike (S) glycoprotein of SARS CoV. Methods Mol Biol. 2007;379:127-35. https://doi.org/10.1385/1-59745-393-5:127 PMid:17502675

18. Zheng J, Yamada Y, Fung TS, Huang M, Chia R, Liu DX. Identification of $\mathrm{N}$-linked glycosylation sites in the spike protein and their functional impact on the replication and infectivity of coronavirus infectious bronchitis virus in cell culture. Virology. 2018;513:65-74. https://doi.org/10.1016/j.virol.2017.10.003 PMid:29035787

19. Fujieda S, Seki M, Tanaka N, Sunaga H, Ohtsubo T, Tsuzuk H, et al. Inhibition of $\mathrm{N}$-linked glycosylation by tunicamycin enhances sensitivity to cisplatin in human head-and-neck carcinoma cells. Int J Cancer. 1999;80(2):279-84. https://doi.org/10.1002/ (sici)1097-0215(19990118)80:2<279::aid-ijc18>3.0.co;2-n PMid:9935211

20. Charley B, Lavenan L, Delmas B. Glycosylation is required for coronavirus TGEV to induce an efficient production of IFN alpha by blood mononuclear cells. Scand J Immunol. 1991;33(4):435-40. https://doi.org/10.1111/j.1365-3083.1991. tb01792.x

PMid:1850168

21. Locker JK, Rose JK, Horzinek MC, Rottier PJ. Membrane assembly of the triple-spanning coronavirus $M$ protein. Individual transmembrane domains show preferred orientation. J Biol Chem. 1992;267(30):21911-8.

PMid:1400501

22. de Haan C, de Wit M, Kuo L, Montalto-Morrison C, Haagmans B Weiss $\mathrm{S}$, et al. The glycosylation status of the murine hepatitis coronavirus $\mathrm{M}$ protein affects the interferogenic capacity of the virus in vitro and its ability to replicate in the liver but not the brain. Virology. 2003;312(2):395-406. https://doi.org/10.1016/ s0042-6822(03)00235-6

PMid:12919744

23. Hogue BG, Nayak DP. Expression of the porcine transmissible gastroenteritis coronavirus $M$ protein. Adv Exp Med Biol. 1990;276:121-6. PMid:1966402

24. Fung T, Liu D. Coronavirus infection, ER stress, apoptosis and innate Immunity. Front Microb. 2014;5:296. http//doi:10.3389/ fmicb.2014.00296

PMid:24987391

25. Delmas B, Laude $H$. Assembly of coronavirus spike protein into trimers and its role in epitope expression.
J Virol. 1990;64(11):5367-75. https://doi.org/10.1128/ jvi.64.11.5367-5375.1990

PMid:2170676

26. White TC, Yi Z, Hogue BG. Identification of mouse hepatitis coronavirus A59 nucleocapsid protein phosphorylation sites. Viru Res. 2007;126(1-2):139-48. https://doi.org/10.1016/j. virusres.2007.02.008

27. Oostra M, Hagemeijer MC, van Gent M, Bekker CP, te Lintelo EG, Rottier PJ, et al. Topology and membrane anchoring of the coronavirus replication complex: Not all hydrophobic domains of nsp3 and nsp6 are membrane spanning. J Virol. 2008;82(24):12392-405. https://doi.org/10.1128/jvi.01219-08 PMid:18842706

28. Chang C, SueSC, YuT.Modularorganization of SARS coronavirus nucleocapsid protein. J Biomed Sci. 2006;13(1):59-72. PMid:16228284

29. Woo PC, Lau SK, Laml CS. Discovery of seven novel mammalian and avian coronaviruses in deltacoronavirus supports bat coronaviruses as the gene source of alphacoronavirus and Betacoronavirus and avian coronaviruses as the gene source of gammacoronavirus and deltacoronavirus. J Virol. 2012;86(7):3995-4008. https://doi.org/10.1128/jvi.06540-11 PMid:22278237

30. Ritchie G, Harvey DJ, Feldmann F. Identification of N-linked carbohydrates from severe acute respiratory syndrome (SARS) spike glycoprotein. Virology. 2010;399(2):257-69. https://doi. org/10.1016/j.virol.2009.12.020

PMid:20129637

31. Angelini MM, Akhlaghpour M, Neuman BW, Buchmeier MJ. Severe acute respiratory syndrome coronavirus nonstructural proteins 3,4 , and 6 induce double-membrane vesicles. mBio. 2013;4(4):e00524-13. https://doi.org/10.1128/mbio.00524-13 PMid:23943763

32. Wong $\mathrm{HH}$, Fung TS, Fang $\mathrm{S}$, Huang $\mathrm{M}$, Le MT, Liu DX. Accessory proteins $8 \mathrm{~b}$ and $8 \mathrm{ab}$ of severe acute respiratory syndrome coronavirus suppress the interferon signaling pathway by mediating ubiquitin-dependent rapid degradation of interferon regulatory factor 3. Virology. 2017;515:165-75. https://doi.org/10.1016/j.virol.2017.12.028

PMid:29294448

33. Lindner HA, Lytvyn V, Qi H, Lachance P, Ziomek E, Menard R. Selectivity in ISG15 and ubiquitin recognition by the SARS coronavirus papain-like protease. Arch Biochem Biophys. 2007;466(1):8-14. https://doi.org/10.1016/j.abb.2007.07.006 PMid:17692280 